\title{
OS CONSElHOS de PARTICIPAÇÃo POPUlaR. VALIDADE JURÍDICA DE SUAS DECISÕES
}

José Reinaldo de Lima Lopes(")

\section{ORIGENS DOS CONSELHOS}

A redemocratização brasileira dos anos 80 culminou com a convocação de um Congresso Constituinte em 1986, instalado em 1987 e que terminou por promulgar a Constituição de 1988. Os anos que antecederam a reconstitucionalização conheceram um movimento original de associacionismo na sociedade brasileira. Já que os mecanismos tradicionais de participação política haviam sido seriamente mutilados durante as décadas do Estado de Segurança Nacional (tais como os partidos políticos), as muitas reivindicações populares foram canalizadas para movimentos sociais de diversa natureza. Durante o processo constituinte, tais movimentos apresentaram-se como atores políticos relevantes e conseguiram, entre outras coisas, incluir no texto constitucional a idéia da participação popular no Estado por meio dos referendos, plebiscitos e iniciativa popular das leis. $\mathrm{Em}$ alguns casos conseguiu-se também que em determinados setores da Administração Pública fosse formalizada a participação da sociedade civil, da comunidade.

Narrada deste ponto de vista, a origem próxima dos conselhos parece democrática e um efetivo avanço político. De fato, os conselhos procuram abrir um espaço institucional em que as classes populares, tradicionalmente excluídas de voz ativa na vida política e jurídica brasileira, possam ao mesmo tempo fazer-se ouvir e deliberar. $E$, no entanto, creio que os conselhos colocam-nos uma série de dificuldades também do ponto de vista da democracia. Em primeiro lugar, podem tornar-se um espaço paralelo ao dos órgãos e poderes tradicionais do Estado: nestes termos ${ }^{(1)}$, ou resultam numa estrutura menos importante, para quem seriam relegadas decisões menos

(“) Procurador do Banco Central do Brasil.

(1) Professor Visitante da Universidade da Califórnia, San Diego. 
importantes, consolidando uma exclusão do povo dos círculos mais internos do poder ${ }^{(2)}$, ou trazem um novo lugar para o debate a respeito da representação. Em segundo lugar, os conselhos podem tentar inserir numa sociedade altamente complexa e diferenciada a velha idéia da comunidade: numa sociedade de massas, de classes e de comunicações e informação uma idéia como esta não deixa de estar cheia de ambigüidades, muitas vezes servindo a um controle da autonomia individual com certo sabor totalitário. Finalmente, os conselhos às vezes guardam um forte sentido corporativista, de difícil convivência seja com o Estado liberal tradicional seja com um Estado social-democrático (Faria, 1993).

Esta última dificuldade ocorre porque o Estado liberal foi instituído pela soma da legalidade (em alguns casos também do constitucionalismo) com a democracia representativa. Democracia representativa significava essencialmente que uma assembléia de cidadãos eleitos por seus pares decidiria soberanamente em nome da Nação. Tratava-se de um sistema jurídico fundamentado em grandes universalizações: lei, vontade geral, vontade nacional, etc. O sufrágio universal ampliou progressivamente o número dos eleitores (o sufrágio universal foi uma das bandeiras do movimento socialista, assim como do movimento das mulheres). As diversas crises econômicas de acumulação ampliaram a função regulatória do Estado, ou, melhor dito, transferiram a regulação do Poder Judiciário (pela execução forçada dos contratos e defesa da propriedade) para o Executivo e Legislativo (pela coordenação concertada da concorrência intra e extra-setorial na economia). Naquele momento histórico (primeira metade do século $X X$ ) abriram-se duas alternativas: uma completa transformação do Estado na direção socialista, ou uma outra transformação de caráter corporativista. A representação corporativa surgiu em grupos paralelos aos poderes formais: para um Parlamento eleito por todos os cidadãos surgiram os grupos de pressão (lobbies) a formar um verdadeiro congresso paralelo (Commons, apud Olson, 1971, pp. 114 e ss.). Estes grupos deram voz a interesses diferentes daqueles universalmente afirmados nos programas dos partidos (atores dos parlamentos). Tenderam a transformar a política numa política de interesses (Cerroni, 1993 , p. 123) e de pauta única (single issue politics). Isto não pode ser creditado ao fato de que os interesses efetivamente em competição na sociedade são muito distintos: cada pessoa naturalmente tem uma participação diversificada em grupos de interesse ou de identidade, uma overlapping membership. O que ocorreu foi uma forma de escapar da avassaladora presença de votantes, uma resposta ao sufrágio universal. O corporativismo, nestes termos, desenvolveu mecanismos de um Legislativo paralelo. $O$ aumento das funções regulatórias do Executivo, por outro lado, gerou as novas agências, autarquias criadas para tarefas especificas em setores determinados da economia. Na experiência brasileira, a regulação fazia-se acompanhar pelo incentivo à acumulação capitalista e ao desenvolvimento (industrialização) nacional. Em torno de tais agentes desenvolveu-se uma pressão por seto-

(2) Centro de Estudos Direito e Sociedade - Faculdade de Direito da Universidade de São Paulo. 
res, interessados em influenciar o planejamento das políticas públicas e a repartição dos custos e beneficios da economia nacional. O corporativismo instalou-se paralelamente ao Executivo. Com o passar do tempo, cresceu a pressão para que conflitos não intermediados e não resolvidos pelo Executivo e pelo Legislativo fossem expressos em disputas judiciais. Grupos de interesses singulares quiseram aparecer em juízo e aos poucos transformaram o processo civil, criando a legitimação dos interesses coletivos, quando não organizando tribunais especiais. $O$ corporativismo afeta também o Judiciário tradicional pelos bem montados grupos acadêmicos que advogam interesses do status quo, em nome da neutralidade e do direito adquirido, pela imprensa e por um circuito de cursos, encontros e seminários (Galanter, 1974; Sunstein, 1993).

Deste ponto de vista, o corporativismo na política foi uma resposta aos desafios da cidadania universal num contexto social e econômico complexo. Uma de suas características permanentes é o destaque dado ao organicismo da sociedade: o todo (a sociedade, ou o Estado que a organiza, coordena ou representa) compõe-se de partes distintas, mas a distinção das partes é funcional. Tendo funções diversas, tendem para um mesmo fim: o progresso, o desenvolvimento, a prosperidade nacional. A política corporativista tende, por causa disso, em segundo lugar, para práticas de concertação e para ênfase no entendimento antes que no conflito. É um sistema de negociação, não um sistema de afirmação de direitos. É a cultura políticà do consenso (Schmitter, 1974).

Assim narrada a história, pode-se perceber que os conselhos populares podem facilmente encaixar-se num modelo corporativista de Estado. Este modelo, embora tenha servido a certa fase do desenvolvimento econômico capitalista, entra agora em crise: a onda neoliberal, para além de uma espécie de orgia ideológica do livre mercado, corresponde à necessidade de liberdade do capital transnacional financeiro. Mas esta mesma onda está carregada de ambigüidades: interessa-se por formas concertadas de liberalização (o antigo GATT e o atual FMI são exemplos claros, ao lado dos esforços de coordenação da União Européia, do Grupo dos Sete, etc.), e na esfera dos Estados Nacionais percebe que as formas concertadas, em algumas ocasiões, resultam em bloqueios mais do que em cooperacão. No caso do Brasil, câmaras setoriais podem ser iniciativas interessantes para o capital, conselhos de saúde talvez não.

\section{OS CONSELHOS NO ORDENAMENTO JURÍDICO BRASILEIRO}

2.1. Dos anos 30 para cá o Estado brasileiro acumulou conselhos de várias naturezas. Em geral, trata-se de órgãos que integram a administração e a justiça. Na Justiça, os conselhos constituem tradicionalmente duas espécies: o conselho de sentença (júri) ou os conselhos da administração da 
máquina judiciária (representados pelos órgãos especiais dos tribunais estaduais, ou pelo conselho da justiça federal).

$\mathrm{Na}$ Administração multiplicaram-se extraordinariamente. Deixando de lado os primeiros conselhos profissionais, ou ordens (OAB, Conselho Federal de Medicina, etc.), surgiram da mais variada natureza: Conselho Nacional do Petróleo, Conselho de Desenvolvimento Industrial, Conselho Monetário Nacional (Lei n. 4.595/64), Conselho Federal de Educação (Lei n. 4.024/ 61), Conselho Nacional de Seguros Privados (Decreto-lei n. 73/66), etc. Diferenciam-se pela composição e pela competência. Quanto à composição, podem incluir apenas membros da própria administração (como o Conselho de Desenvolvimento Industrial, que era um conselho de Ministros de Estado de áreas afins) ou incluir representantes das próprias indústrias ou atividades reguladas pelo Conselho (caso do Conselho Federal de Educação, ou das antigas comissões anexas do Conselho Monetário Nacional).

Quanto ao preenchimento de suas vagas, em geral escapam do mecanismo da eleição direta e universal. Seus membros podem ser indicados por autoridade pública, indicados por grupos privados; ou se trata de membros natos, por se tratar de ocupantes de certos cargos ou funções. Os membros do Conselho Monetário Nacional, por exemplo, são parcialmente natos, parcialmente nomeados pelo Presidente da República: são membros natos o Ministro da Fazenda, os presidentes do Banco Central do Brasil, do Banco do Brasil e do BNDE. São nomeados livremente pelo Presidente da República outros seis membros, aprovados pelo Senado Federal, desde que contém com notória capacidade em assuntos econômico-financeiros (Lei n. 4.595/ 64 , art. $\left.6^{\circ}\right)$. O CMN é típico do Estado regulador de ação concertada: contando com membros da sociedade civil, não é um órgão de representação popular.

No que diz respeito a sua competência, chamam-se conselhos certos órgãos normativos, assim como certos órgãos adjudicadores (judicantes em contencioso administrativo) ou ainda colegiados que apenas aconselham certas práticas (como $\circ$ antigo $\mathrm{CDI}$ ), consultivos. $\mathrm{O}$ Conselho Monetário Nacional é tipicamente normativo, o Conselho Especial de Recursos do Sistema Financeiro é tipicamente contencioso, assim como os diversos ConseIhos de Contribuintes. O Conselho Administrativo de Defesa Econômica, hoje uma autarquia, desempenha funções de polícia do poder econômico e contenciosas. O Conselho Federal de Educação acumula funções normativas e contenciosas, e o Conselho de Defesa dos Direitos da Pessoa Humana é acima de tudo um investigador de denúncias, aconselhando medidas e encaminhando casos a um Poder ou outro.

Quando normativos, os conselhos em geral têm poderes de regulamentar a legislação propriamente dita, isto é, os atos do Congresso com caráter de lei, ou os atos do Executivo. Por isso, os conselhos submetem-se, dentro da hierarquia das leis, à mesma situação de qualquer órgão administrativo. Isto do ponto de vista formal, pois do ponto de vista material eles 
tendem a ser importantes alimentadores do processo legislativo com sugestões e estudos.

Como se executam as decisões dos conselhos? Há formas diferentes. No caso do sistema financeiro, por exemplo, o Banco Central funciona como executor das decisões normativas do CMN (que tomam a forma de Resoluções), comunicando-as aos integrantes do mercado financeiro por meio de suas próprias Circulares ou Cartas Circulares (conforme o caso), e, sobretudo, dispõe do poder de polícia: nesse sentido, pode conceder e cassar autorizações, impor sanções administrativas por meio de contencioso administrativo, etc. O mesmo se pode dizer do Conselho Federal de Educação, que toma resoluções e regula as atividades de estabelecimentos de educação, ao mesmo tempo em que pode exercer o poder de polícia, concedendo ou negando autorizações, credenciando e descrédenciando cursos, impondo sanções administrativas, etc.

2.2 Em que esta prática consolidada no direito brasileiro se distingue dos novos conselhos de participação popular? $\mathrm{Na}$ Constituição Federal de 1988 há diversas referências à participação da comunidade. O art. 194, VII, menciona-a no âmbito da gestão da previdência social. A previdência é tipicamente uma esfera de administração tripartite, já que os fundos que a compõem resultam de contribuições estatais, patronais e de trabalhadores. $O$ art. 198, III, refere-se à participação comunitária no âmbito da saúde pública. O art. 204, II, amplia-a para o campo da assistência social. Finalmente o art. 206, VI, contempla-a na educação. Esta pequena lista traz imediatamente à lembrança o texto do art. $6^{2}$ da Constituição, que define como direitos sociais a educação, a saúde, o trabalho, o lazer, a segurança, a previdência social, a proteção à maternidade e à infância, a assistência aos desamparados. É possível estabelecer uma primeira ligação entre direitos sociais e participação popular: o texto constitucional indica, no que diz respeito aos direitos sociais, que planejamento e execução de políticas públicas precisam de algo mais do que a representação universal do parlamento.

Esta hipótese coloca, porém, uma série de dificuldades tradicionais para a teoria democrática do Estado. Parece ser uma forma de devolução de poderes para a sociedade civil. Se assim for, no entanto, deslocam-se para esta esfera os problemas tradicionais da representação, da escolha dos representantes que têm assento nos conselhos, já que a sociedade civil pode muito bem ser o campo minado das inúmeras contradições de interesses particulares não articulados, desorganizados. Desloca-se para aí também o problema fundamental do monopólio do particularismo e dos interesses locais dominantes (locais ou setoriais). Muitíssimos direitos fundamentais de grupos e grupos sociais oprimidos, marginalizados ou explorados só se viabilizaram na história quando as formas locais de opressão foram neutralizadas pela intervenção externa de outros poderes e a história recente nos fornece exemplo aqui e ali (o caso das intervenções federais para garantir direitos civis aos negros no Sul dos EUA, ou as redes de apoio aos presos políticos brasileiros nos anos da ditadura de Segurança Nacional). 
Presumindo que o modelo traçado na Constituição é este de devolução de autonomia popular, há duas coisas a destacar. Em primeiro lugar existe uma histórica e bem fundada desconfiança na capacidade de a representação formal (parlamentar) e dos mecanismos estatais de execução (law enforcement) tradicional (administração e justiça, incluído o Ministério Público e a polícia). Os conselhos seriam remédios contra a omissão continuada do Estado na tarefa de incorporação de cidadãos aos benefícios comuns da vida política. Em segundo lugar, os conselhos dentro desta perspectiva devem cumprir o papel de agentes planejadores e fiscalizadores das políticas públicas. Em ambos os casos, os meios de que dispõem serviriam para neutralizar o fenômeno conhecido em toda parte da captura do Estado regulador pelos interesses que deveria controlar e restringir, tornando-se presa do facciosismo e da falta de prestação de contas - electoral unaccountability (Sunstein, 1987, p. 213). Um órgão estatal criado para fiscalizar um setor de atividade termina por tornar-se prisioneiro do setor: seus profissionais são recrutados no mesmo mercado e continuamente seus presidentes ou responsáveis saem das fileiras do setor regulado, assim como os dados e estudos muitas vezes procedem da indústria ou serviço fiscalizado mais do que dos usuários e consumidores.

2.3 Para analisar os novos conselhos, tomemos dois exemplos: os Conselhos de Saúde e os Conselhos criados pelo Estatuto da Criança e do Adolescente (Conselho de Defesa dos Direitos da Criança e Conselhos Tutelares). Os Conselhos de Saúde acham-se contemplados na Lei n. 8.142/90, por complementação à Lei n. 8.080/90. Os Conselhos de Defesa e ConseIhos Tutelares estão disciplinados, de modo geral, no Estatuto da Criança e do Adolescente. De modo geral, porém, pode-se dizer que os conselhos estão destinados a duas funções: formulação de políticas e controle de sua execução (Constituição Federal, art. 204, II).

A questão da validade das deliberações dos Conselhos que contam com a participação popular ou da comunidade coloca-nos diante de um dos mais complexos problemas da teoria jurídica atual. Validade de determinada norma quer dizer ao mesmo tempo sua pertença ao ordenamento jurídico e, por conseqüência, sua obrigatoriedade, ou seja, sua capacidade de criar direitos e obrigações, sua capacidade para criar deveres jurídicos. Nestes termos, se os Conselhos estão incluídos na ordem constitucional e legal, suas decisões pertencem de algum modo ao ordenamento. Pertenceriam na mesma qualidade que uma decisão judicial, ou uma decisão parlamentar com forma de lei, ou um ato administrativo (seja de execução, como os atos de polícia, seja de regulamentação, como os decretos e atos normativos)? Creio que o centro da discussão deve ser temporariamente deslocado para o que fazem os Conselhos e para a maneira como deliberam.

2.3.1 Quanto ao que fazem pode-se resumir em planejamento e controle. $O \S 2^{2}$ do art. $1^{\circ}$ da Lei $n$. 8.142/90 diz que o Conselho "atua na formulação de estratégias (...) da política de saúde na instância correspondente, inclusive nos aspectos econômicos e financeiros". Diz também que suas de- 
cisões serão "homologadas pelo chefe do poder legalmente constituído". Assim, em primeiro lugar o que faz um Conselho desta natureza não é um ato de adjudicação. Não se refere a eventos passados, e nem se refere a indivíduos em particular. Não reconhece ou atribui a alguém a titularidade de alguma coisa. Formula estratégias de política de saúde, ou seja, estabelece planos para o futuro, planos que integram objetivos a realizar ou alcançar, prioridades de ação e execução de tarefas, alocação de recursos: em outras palavras, o Conselho planeja ações e distribui recursos em vista de tais planos. Mas não distribui os recursos que quer, senão aqueles de que dispõe. Isto porque os recursos ou são orçamentários (ver art. $194 \mathrm{c} / \mathrm{c}$ art. 195 da Constituição Federal), ou se trata de recursos privados que se integram a uma política de saúde. É de se lembrar também que no art. $200 \mathrm{da}$ Constituição Federal constam as competências do sistema único de saúde, que terminam, a meu ver, por se estender também aos Conselhos, nas suas respectivas esferas de governo.

Assim encarada, a funçāo dos Conselhos apresenta os traços gerais de toda norma de planejamento (Grau, 1977, p. 78). Referindo-se ao futuro, tem um caráter instrumental e naturalmente flexibilidade. Pode ser revista com freqüência e nisto cria uma aparente contradição com o princípio tradicionalmente aceito do direito adquirido. Ou seja, uma vez feito um plano de política de saúde, os usuários ou beneficiários adquirem direitos individuais e subjetivos a sua continuidade, mesmo que surja uma emergência (imagine-se uma epidemia) a exigir recursos imediatos e extraordinários para salvar outras tantas vidas? Ou, dada a mesma situação de emergência, podem os hospitais e clínicas particulares, que de alguma forma contavam com recursos distribuídos (pagos) pelo SUS, alegar inadimplemento de uma obrigação explicitada em normas de planejamento? A resposta que proponho é negativa. Justamente porque se trata de norma (decisão ou deliberação) instrumental o plano cria apenas expectativa de direitos, nos termos da dogmática (doutrina) jurídica privatista. Isto, porém, não torna a decisão ou deliberação do Conselho menos jurídica. $O$ relevante é que seu objeto não é, como já dito, adjudicar interesses singulares, mas deliberar sobre critérios que digam respeito à saúde pública, ou seja, a condições mínimas e comuns para a "redução do risco de doença e de outros agravos e ao acesso universal e igualitário para sua promoção, proteção e recuperação" (art. 196 da Constituição Federal). Nesse sentido, o dever do Estado é uma obrigação de meios, não de resultados: não se pode segurar contra a doença ou a morte, no sentido de evitá-las. Pode-se tomar medidas que minimizem suas conseqüências, mas tais medidas são impessoais e gerais, dizem respeito ao risco, que se mede por estatística (Stewart e Sunstein, 1982, p. 1273; Sunstein, 1993, pp. 319 e ss.; Ewald, 1986, pp. 343/345). A redução do risco não pode dar a cada indivíduo em particular o mesmo direito que uma troca de coisas: nesse sentido, o direito social distingue-se do direito individual tradicional, como já tenho afirmado em diversas ocasiões, da mesma forma que a justiça distributiva se distingue da justiça comutativa, corretiva ou compensatória. 
A deliberação dos Conselhos equivale a uma simples proposta ou é vinculante para o "chefe do poder legalmente constituído em cada esfera do governo" (art. $1^{2}, \S 2^{2}$, in fine, da Lei n. 8.142/90)? Qual o sentido da expressão "homologadas no mesmo texto legal"? Aqui um dos centros da questão, que envolve, parece-me, diretamente 0 arcabouço jurídico-político do Estado contemporâneo. Duas hipóteses: (1) a homologação pelo chefe do poder é, para este, ato vinculado, ou seja, dispensa-o de deliberar sobre a questão; (2) a homologação é ato discricionário, e, assim como no sistema tradicional de divisão de Poderes, bloqueios recíprocos (freios e contrapesos) permitem ao Executivo vetar atos do Legislativo, haveria poder de veto no caso. Não é fácil decidir. As dificuldades que vejo dependem do fato seguinte: o chefe do poder foi eleito, bem ou mal, com todos o defeitos de que padece nosso sistema eleitoral e partidário. Em tese, pois, ocupa uma posição que Ihe dá a legitimidade para implantar um programa de governo. Os ConseIhos, sendo setoriais, contando com a representação de interesses particulares (dos hospitais?, das seguradoras?, de usuários?, etc.), escapam do controle do sufrágio universal. Por outro lado, se considerarmos uma das razões de ser dos Conselhos, justamente uma tentativa de interferir num sistema político tradicionalmente insensível a prioridades sociais, seria o caso de ver neles exatamente esta função de escapar o sistema partidário eleitoral viciado. Nestes termos, embora o chefe do poder possa vetar a proposta, isto é, não homologá-la, talvez não possa substituir-se ao Conselho na sua formulação. Neste caso, pode-se reproduzir nesta esfera setorial o mecanismo de bloqueio que existe entre Executivo e Legislativo. A saída não pode ser um impasse permanente, um poder de bloqueio recíproco sem alternativa. Seria razoável supor que o Conselho pode ter uma decisão não homologada caso haja motivo fundado: irregularidade, ilegalidade, etc. De outro modo, parece que na sua esfera espacial de competência (local) e na sua esfera setorial (políticas localizadas e definidas de saúde) o Conselho goza de autonomia. Esta autonomia fica limitada pelos recursos que the são destinados pelo Legislativo e pela necessidade de coordenação das diversas demandas dos diferentes Conselhos locais, naturalmente, constituindo-se isto um motivo para a não-homologação de suas decisões.

o Conselho atua também "no controle da execução da política de saúde na instância correspondente, inclusive nos aspectos econômicos e financeiros" (art. $1^{2}, \S 2^{\circ}$, da Lei n. 8.142/90). A política de saúde tem, como toda política pública, um caráter instrumental. Se 6 certo que se trata de um dever de meios e não de resultados, existe a possibilidade de se indagar da adequação dos meios para atingir certos resultados. Mais ainda, a eleição de prioridades também não é totalmente livre. Em última instância, mesmo que absolutamente genérica, a Constituição Federal deu ao Estado brasileiro objetivos (art. $3^{\circ}$ ), entre os quais o de erradicar a pobreza e a marginalização e reduzir as desigualdades sociais e regionais, promover o bem de todos sem preconceitos e construir uma sociedade livre, justa e solidária. Certo que tais princípios tão fundamentais chegam a ser quase tautológicos. Mesmo assim, quando combinados mais concretamente com propostas orça- 
mentárias; leis de diretrizes orçamentárias, estrutura fiscal e administrativa e certo saber sobre a estrutura social e a conjuntura econômica, permitem ver que certos planos apresentam objetivos inalcançáveis ou contraditórios com os meios empregados naquele particular setor. Os Conselhos seriam legitimados a discutir tais planos, assim como a forma de execução de tais políticas e, sobretudo, deveriam ser legitimados - de fato deveriam ser obrigados - a apresentar alternativas imediatas para o plano ou política em desenvolvimento. Algo como o voto de desconfiança construtivo existente na Lei Fundamental de Bonn de 1949 da Alemanha Federal.

2.3.2 O caso dos Conselhos Tutelares definidos na Lei $n$. 8.069/90 (Estatuto da Criança e do Adolescente) é diferente. $O$ art. 131 do ECA, que institui o Conselho Tutelar, cria-o como órgão permanente e autônomo, não jurisdicional, encarregado pela sociedade (?) de zelar pelo cumprimento dos direitos da criança e do adolescente. Os Conselhos aqui não são formuladores de planos, mas sobretudo executores e supervisores com certos poderes. Não dispõem de um poder totalmente autônomo, na medida em que sua competência está muitas vezes restrita a encaminhar os casos a uma autoridade (administrativa ou judicial) competente. Por outro lado, 0 art. 136 dá-Ihes competência para atender crianças, em geral prestar assistência em caso de violação de seus direitos. Por isso, podem zelar por direitos em casos individuais. São também colaboradores paralelos do Judiciário (art. 136, VI) e do Executivo (art. 136, IX), na medida em que devem assessorá-los na elaboração do orçamento para planos ou programas de atendimento a menores (aqui um potencial conflito com as atribuições do Conselho dos Direitos da Criança).

Um dos problemas mais claros dos Conselhos Tutelares está na forma como foram definidos, ou seja, como órgãos encarregados pela sociedade de zelar pelos direitos das crianças. O uso da expressão "sociedade" quer dizer certamente que não são encarregados pelo Estado. Mas a expressão é pouco feliz, pois o problema de quem representa a sociedade é, para dizer o minimo, complexo. A tentativa de retirar os Conselhos Tutelares da moldura estatal também é evidente no uso da expressão "comunidade local", quando definindo amplamente quem os elege (art. 139). Quem compõe a comunidade? A linguagem aqui usada serve para lembrar-nos duas coisas: (1) é fruto dos movimentos sociais dos anos 70 e 80 , quando a redemocratização desenvolveu-se contra o Estado e paralelamente ao Estado (Cardoso, 1994, p. 86); (2) tende para uma concepção excessivamente positiva da comunidade, que me parece apontar para uma tradição pré-moderna de organização social (comunidades tradicionais, como família, igreja e vizinhança) claramente inadequada para a vida urbana industrial, ao mesmo tempo em que tende para formas corporativistas de organização, em que o Estado volta a ter paradoxalmente um papel central.

Já os Conselhos dos Direitos da Criança e do Adolescente (municipais, estaduais e nacional - este regulado pela Lei $n$. 8.242/91) são definidos como órgãos deliberativos e controladores, com participação popular 
(art. 88, II, do ECA). A Lei n. 8.242/91 encarrega o Conselho Nacional dos Direitos da Criança e do Adolescente (Conanda), entre outras coisas, de elaborar normas gerais da política nacional de atendimento dos direitos da criança e do adolescente e fiscalizar as respectivas ações de execução. Seus membros dividem-se em representantes do Poder Executivo, assegurado número igual de representantes de entidades não governamentais de âmbito nacional de atendimento dos direitos da criança (art. $3^{2}$ ). Dessa forma, apresenta os mesmos problemas já vistos com os Conselhos de Saúde, tanto no campo da representação quanto no da validade de sua decisões. Pode-se, pois, aplicar-lhes as mesmas considerações anteriores.

\section{CONCLUSÃO}

Os órgãos colegiados em cuja composição entrariam representantes da comunidade ou da sociedade formulam políticas públicas e exercem alguma função executiva e fiscalizadora. Correspondem a uma tentativa de ampliação do controle democrático dos órgãos estatais em geral (em qualquer dos Poderes) e procuram ultrapassar os muitos filtros que uma política eleitoral partidária coloca aos interesses dos menos capazes. Ao mesmo tempo, enfrentam problemas reais quanto a sua efetividade para este fim. Alguns deles são apontados por Sartori (Sartori, 1994, pp. 306/316) e nos interessam particularmente aqui. Destaco dois. Primeiro, o fato de que nos comitês (nos pequenos grupos institucionalizados e permanentes para tomadas de decisões concretas nas democracias) a sua existência continuada vai impondo uma cultura da conciliação. Mesmo que se decida por maioria, de fato a unanimidade se insinua "porque cada componente do grupo espera que aquilo que concede numa questão Ihe seja devolvido, ou retribuído, em uma outra questão" (p. 306). Segundo, que, embora eles mesmos sejam unidades ótimas de participação, esta participação é dos que estão dentro, criando naturalmente um espaço dos que estão fora. Por isso, tornam-se necessários comitês de representação (p. 312), cujo objetivo é criar receptividade e responsabilidade perante as demandas dos representados.

Do ponto de vista da democracia, os Conselhos apresentam também - problema da oligarquização das representações: quem chegará a ter assento e voz nos conselhos? Quem falará pela comunidade? Caso o interesse da comunidade possa ser univocamente definido, isto terá pouca importância: a reivindicação de asfaltamento em certa rua de certa comunidade pode facilmente gerar um conselho de vizinhos. Mas o conselho terá a mesma qualidade quando for deliberar, por exemplo usando a imaginação, sobre o currículo da escola do bairro? Será que aí algumas diferenças entre vizinhos brancos e negros, paulistas, pernambucanos, crentes, espíritas, afros, famílias nucleares e mães solteiras já não terão pesos distintos e perspectivas diferentes (contrastantes)? Os conselhos tendem a transformar-se em uma ordem corporativa, na qual projetos globais são difíceis e estratégias 
defensivas de curto prazo se multiplicam (Tapia, 1994, p. 69). Seja por indicação, seja por eleições em que o eleitorado não é universal, o conselho pode ao mesmo tempo ser tanto um mecanismo de aproximação popular da esfera de poder e decisão quanto uma ferramenta de elitização: nada disso é certo.

Vale lembrar também que os conselhos estão diretamente relacionados, nos casos acima comentados, à efetivação dos direitos sociais constitucionais, que exigem prestações estatais positivas (Silva, 1992, p. 258) e políticas públicas (Lopes, 1994). Deste ponto de vista, encontram-se justamente no local em que as diferenças sociais exigem tomada de posição incapaz de no curto prazo beneficiar a todos simultaneamente. As alternativas são sempre distributivistas, aumentando - ou conservando - o quinhão dos que já têm, ou aumentando o quinhão dos que não têm. Uma estratégia setorial de apropriação dos fundos públicos é sempre melhor do que nada, mas é insuficiente.

Por causa disto, embora se possa dizer que as decisões dos consethos são vinculantes para a Administração, talvez o mais adequado seja dizer que são vinculantes na esfera de autonomia do próprio conselho e não quando se tratar de esfera em que se exija coordenação de diferentes níveis e esferas de governo.

Os conselhos com participação da comunidade ou da sociedade pretendem ser um mecanismo de influência sobre a Administração. Explicamse e justificam-se como meios de controle público sobre fundos públicos: pretendem, portanto, dar visibilidade e responsabilidade (accountability). Pretendem também aumentar a participação e a educação cívica dos cidadãos. São uma resposta ao liberalismo brasileiro, liberalismo elitista, que jamais produziu um igualitarismo institucional (pois a sociedade brasileira insiste em formas pré-liberais e pré-democráticas de estratificação e diferenciação), jamais produziu um igualitarismo econômico (pois entre nós o utilitarismo ético de um J.S. Mill jamais serviu de fundamento moral para o capitalismo tropical), jamais produziu um igualitarismo de respeito à identidade e dignidade do outro (o escravismo e a dominação paternal-patriarcal sempre foram incompativeis com a noção universal de respeito e de autonomia dos sujeitos). Nosso liberalismo foi incapaz de produzir um pensamento igualitário vigoroso como o de $H$. D. Thoreau, ou como os de nossos contemporâneos John Rawls, Thomas Nagel e Ronald Dworkin. Ateve-se, e atém-se até hoje, ao discurso de um laissez faire individualista e hobbesiano no que diz respeito às atividades econômicas, e ao discurso moralista - capaz até de justificar a censura - no plano dos bons costumes (patriarcais).

Nestes termos, os conselhos de participação popular poderiam ser um avanço, pois introduziriam em nosso Estado a cunha das grandes massas de marginalizados. Mas para que isso fosse possivel duas condições institucionais se apresentam: em primeiro lugar, que a participação nos conselhos seja limitada aos usuários ou consumidores dos setores produtivos sobre os 
quais tais conselhos têm ou podem ter competência. Em segundo lugar, que os mecanismos de participação e eleição estimulem efetivamente a alternância nos cargos ou pelo menos permitam arejar os conselhos, de modo a evitar que as oligarquias se formem e dominem (lembrando a célebre lei de ferro das oligarquias partidárias expressa por Robert Miche/s). Tais dispositivos tenderiam a evitar que os conselhos caíssem na concepção organicista e na cultura do consenso típica do corporativismo (pois os sujeitos da regulação estariam excluídos do conselho, dificultando a troca dos votos) e dificultariam a consolidação de minorias não representativas.

Não só o corporativismo (facciosismo) é uma ameaça ao desenvolvimento democrático das políticas públicas. $O$ autoritarismo é sua outra face. $O$ autoritarismo tem muitas vezes a face doce do paternalismo (a dominação pelo amor, de que fala José Comblin) e do comunitarismo. A face doce do paternalismo dificulta o surgimento do cidadão autônomo e capaz (Offe e Preuss, 1993). O comunitarismo tende para uma confusão entre 0 ideal de relações comunitárias próximas (o sonho perdido com a urbanização industrial) e a realidade das opressões cotidianas do pequeno mundo dos horizontes homogêneos. Uma concepção comunitária da vida humana não pode levar-nos a uma concepção comunitarizante de instituições de sociedades complexas. "A polis pode talvez servir de metáfora à sociedade política moderna; não pode servir-Ihe de modelo" (Hirsch, 1992, p. 257). A comunidade tampouco pode ser, do ponto de vista moral, a comunidade real. Ela é um ideal, uma comunidade de sujeitos transparentes e bem-intencionados, ela também é um fim. Não se pode tomar o fim como o dado do qual se parte para a organização dos conselhos. O comunitarismo também pode ser um autoritarismo.

A regulamentação dos conselhos precisa levar em conta, portanto, dois aspectos contrastantes do fenômeno. Em primeiro lugar o caráter democrático da experiência, ao dar visibilidade, transparência e publicidade a certos temas que de outra forma ficariam relegados a gabinetes e sujeitos a maior influência dos interesses organizados e consolidados sob a capa da neutralidade do direito adquirido (status quo). Impondo a discussão, os conselhos trazem a público as divergências. O outro lado da questão, porém, é evitarse a paralisia decisória, a corporativização dos espaços de participação e a estreiteza do comunitarismo e do particularismo. Os conselhos, embora essenciais, só realizam um papel democrático efetivo se houver instâncias de articulação capazes de propor medidas universais e igualitárias, inclusivas e não exclusivas das massas marginalizadas economicamente ou das minorias oprimidas social e culturalmente.

\section{REFERÊNCIAS BIBLIOGRÁFICAS}

Cardoso, Ruth C. L. (1994) "A Trajetória dos Movimentos Sociais", org. Evelina Dagnino, in Anos 90: Política e Sociedade no Brasil, São Paulo, Brasiliense, 1994. 
Cerroni, Umberto. "Política", trad. Marco Aurélio Nogueira, São Paulo, Brasiliense, 1993.

Ewald, François. "L’Etat Providençe”, Paris, Bernard Grasset, 1986.

Faria, José E. "Direito e Economia na Democratização Brasileira", São Paulo, Malheiros, 1993.

Galanter, Marc. "Why the Haves Come Out Ahead: Speculations on the Limits of Legal Change", Law and Society Review, 1997, n. 9.

Grau, Eros R. "Planejamento Econômico e Regra Jurídica", São Paulo, tese, 1977.

Hirsch, H. N. "A Theory of Liberty: The Constitution and Minorities", New York/London, Routledge, 1992.

Lopes, José R. de L. "Direitos Sociais e Direitos Subjetivos", org. J. E. Faria, in Direitos Humanos, Direitos Sociais e Justiça, São Paulo, Malheiros, 1994.

Offe, Claus e Preuss, Ulrich. "Democratic Institutions and Moral Resources", ed. David Held, in Political Theory Today, Cambridge, Polity, 1993.

Olson, Mancur. "The Logic of Collective Action", Cambridge/London, Harvard Univ. Press., 1971.

Sartori, Giovanni. "A Teoria Democrática Revisitada", trad. Dinah de A. Azevedo, São Paulo, Ática, 1994.

Schmitter, Philippe C. "Still the Century of Corporatism?", in The New Corporatism, Notre Dame, 1974.

Silva, José Afonso da. "Curso de Direito Constitucional Positivo", São Paulo, Malheiros, 1992.

Stewart, Richard e Sunstein, Cass. "Public Programs and Private Rights", Harvard Law Review, 1982.

Sunstein, Carl R. "Constitutionalism After the New.Deal", Harvard Law Review, 1987. Univ. Press., 1993.

"After the Rights Revolution", Cambridge/London, Harvard . "The Partial Constitution", Cambridge/London, Harvard Univ. Press., 1993.

Tapia, Jorge Rubem Biton. "Corporativismo Societal no Brasil: uma Transição Incompleta?", org. Evelina Dagnino, in Anos 90: Política e Sociedade no Brasil, São Paulo, Brasiliense, 1994. 